\title{
Perception and Challenges for Sustainable Construction in Developing Countries: North Cyprus Case
}

\author{
Abbas Elmualim ${ }^{1}$ and Doğa Alp ${ }^{2}$ \\ 1. Faculty of Natural and Built Environment, University of South Australia, Adelaide SA 5000, Australia \\ 2. School of Construction Management and Engineering, University of Reading, Reading RG6 6AW, UK
}

\begin{abstract}
Sustainable construction, together with sustainability, is a growing concern in developed countries in order to influence construction organizations to make "achieving sustainability" in their projects a stringent prior objective. North Cyprus is a rapidly developing country with an annual economic growth of $7 \%$. Construction became the leading sector within the economy after the boom in demand for holiday and retirement houses especially from English and German holidaymakers. Due to lack of government policy on sustainability, developers usually use traditional ways of construction, and the lack of an established link with international construction, which would help local developers be aware of the latest technology and sustainable building techniques, is the main challenges for North Cyprus construction sector to develop sustainable construction practices.
\end{abstract}

Key words: Sustainable development, construction industry, North Cyprus and developing countries.

\section{Introduction}

In the last few decades, there has been a considerable increase in the global environmental awareness. This is mainly due to the emerging environmental problems such as climate change, energy and water problems, habitat loss and deforestation. Emergence of these issues and the rising awareness has resulted in efforts being focused on finding solutions. The outcome of these efforts was that, there was a need to embrace and implement requirements of sustainability and sustainable development in our lives [1]. Sustainable development in general and sustainable construction, in particular, aims to reduce the effects of human activities on the environment and at the same time, makes the best possible contribution to the economy and the social life [2].

Construction sector uses energy, materials, water and land in order to carry out its operations. It is responsible for highest amount of green house gas

Corresponding author: Abbas Elmualim, Ph.D., professor, research fields: sustainable architecture and construction management. emissions, which use vast amount of natural resources and produces vast amounts of waste [3]. Products of the sector are durable, lasting for years and form an unavoidable part of human life and hence affect human life. Therefore, the global construction sector must without any doubts, familiarize itself with the concept of sustainable development and transform its structure from traditional to modern sustainable construction [4]. Sustainable construction, together with sustainability is a growing concern in developed countries. There is a great work being conducted in order to influence companies to make "achieving sustainability" a prior objective in projects delivery $[4,5]$.

Achieving sustainable construction has become a global challenge, which is even bigger for developing countries due to the fact that these countries also have to deal with the problems resulting from continuing development [6]. However, developing countries such as North Cyprus have the opportunity of not making the same mistake as the developed countries, which was, implementing sustainable construction after completing the development phase [7]. According to 
Mukellef and Oguz [7], North Cyprus is a rapidly developing country with an annual economic growth of $7.6 \%$ in 2006 and GDP (gross domestic product) per capita of US $\$ 11,000$ in 2005 compared to US $\$ 4,600$ in 2001. Construction became the leading sector within the significant increase in demand for holiday and retirement houses especially from foreign buyers, mainly due to positive momentum created by political progress in the Cyprus problem. Today, construction sector is the main booster of the rapidly growing and expanding economy. In such an environment, where construction is the leading sector, urgent attention must be paid to sustainability issues [8]. This paper investigates and document the perception and barriers to achieving sustainable construction in a developing country-North Cyprus, using a thorough literature review, questionnaire survey and interviews.

\section{Sustainable Development: The Debate}

The term "sustainability" was first used by the World Council of Churches in 1974. It was put forward by western environmentalists in return to objections from developing countries to worrying about the environment where people in many parts of the world suffered from poverty and deprivation. After this, sustainable development was mentioned by International Union for Conservation of Nature and Natural Resources in 1980. The terms "sustainability and sustainable development" were afterwards mentioned by the United Nations' World Commission on Environment and Development in their report called "Our Common Future", where they secured a permanent place on everyone's agenda. This report is also known as the Brundtland Report as the conference was chaired by the former Norwegian prime minister Gro Harlem Brundtland. The report defined sustainable development as "development that meets the needs of today without compromising the ability of future generations to meet their own" [9]. The slogan "sustainable development" was quickly embraced by governments and other international agencies [10]. In Agenda 21 - the action plan declared in Rio in 1992, sustainability was described as a three-dimensional model as in the Brundtland Report [9]. The model included economy, ecology and society and according to the model, sustainability was at the intersection point of these three components. However, this definition of sustainability was criticized by the German Council of Environmental Advisors. The council explained the ideas of sustainable development as an "ecologically-focused" concept, in which social and economic issues play an important role as natural resources might be replaced with material or human and knowledge, capital only in a low degree. As a result, according to the modern model of sustainable development, society and economy exist as a subset of the environment. Due to the fact that the terminology was new at that time, there were a variety of comments, objections, support and different understandings of what it actually was. Even today, there are misunderstandings and misconception of sustainable development [10].

It is argued that all conventional forms of development are unsustainable as it aims to improve things in the short term and does not take into account the fact that future generations will have to deal with the results of haphazard development [11]. In opposition, sustainable development seeks to improve the general quality of life, including the environment and the society. Sustainability is, therefore, needed to change this improper way of development [12]. Sustainability necessitates those who are lavish to adapt lifestyles within the carrying capacity of the earth, such as reducing the amount of energy used. It is a fact that rapid and uncontrolled growth can cause too much stress on the earth's structure $[6,9,12]$.

\section{Construction and Sustainable Development}

Construction industry is the largest and most fragmented industry. The global output of the construction industry in 2012 was $\$ 4.6$ trillion. It 
accounts for approximately $40 \%$ of all resource consumption and produces $40 \%$ of all the waste including green house gas emissions [13]. Rodwin [14] argued that construction industry is unique in its ability to facilitate development by providing directly for human needs, stimulating investment and generating employment. It is concerned with the production and maintenance of the built environment and produces durable assets. Large scale fragmentation within the industry, especially between design and build reduces the efficiency.

The industry provides the necessary infrastructure for further development in other sectors. Estimating the size of the construction sector within the economy is difficult due to under reporting and informal employment. However, construction sector is one of the leading contributors to the national income in most countries, especially in developing ones. Additionally, construction does not only add to national income while the construction process but also add to wealth while buildings are in use. More than $50 \%$ of the inputs used in the construction are procured from other sectors. Economic sectors are divided into three sub-sectors: (1) these are primary, which includes raw material sectors; (2) which includes manufacturing sectors and lastly tertiary; (3) which includes distribution and application of goods. The industry buys services from all these sub-sectors and for this reason, is a lead sector and hence an increased activity in this sector stimulates all of these sectors.

Construction sector should, without any doubt, should be one of the first sectors in which sustainability requirements are met. There are several reasons for this. Firstly, construction is, in some cases, responsible for serious environmental damages. It uses vast amounts of materials and resource. It was discussed that the construction industry uses most raw materials than any other industry [11].

Second, the industry itself is vitally important. It provides the necessary infrastructure for additional development in all other areas. Additionally, it is one of the most essential contributors to any economy and often used as a tool to stimulate it. The industry is also important as it is one of the key determinates of the quality of life. It is responsible for the built environment including the buildings and the infrastructure. These structures significantly affect the quality of life for the society for a long period, as the built environment is durable.

The construction industry has economic, social and environmental impacts. Being one of the most challenging issues for the industry, sustainable construction aims to find the optimum balance between these issues. By doing so, certain benefits will also be secured. The firms will benefit from the increased profitability as a result of the efficient use of resources including materials, water and energy. The businesses will also avoid adverse publicity by acting more responsible and hence gain a competitive advantage [15].

\section{Method of the Study}

In this paper, a study for perception, barriers and problems to achieve sustainable construction in North Cyprus was conducted. Data and information required to meet the objectives of the study were collected in various ways. An in-depth literature review was conducted to inform the research work. The data and information required in order to present the barriers of sustainable construction in North Cyprus was mainly sourced from the interviews and questionnaires, together with statistics taken from the various sources acknowledged within the text where appropriate. The interviews were made with politicians, contractors and developers, and a non-governmental organization (eight interviews in total). Politicians interviewed include two senior politicians and the head of Governmental Office for Environmental Protection. Additionally, the president and the vice-president of the National Association of Building Contractors were also interviewed. Furthermore, owners of four construction and development companies were 
interviewed as well. The interviews and questionnaires aimed to investigate the following:

- the perception of the idea of sustainability and its place on the agenda;

- the barriers of sustainable construction in North Cyprus;

- problems associated with the construction sector;

- possible solutions for the problems of the sector and the barriers for sustainable construction.

\section{Perception and Challenges of Sustainable Construction}

As a developing country, construction in North Cyprus is recently experiencing an intense period. Once almost solely responding to local demand, the construction industry has in 2003 faced a significant increase in demand caused by foreign buyers. This circumstance is inevitably placing a stress on the environment and has recently been the centre point of discussion for the environmentalists.

Like most of the other countries, North Cyprus is also having difficulty in implementing sustainable construction policy at all levels. Even though both the government and the companies are aware of the need for the sustainable construction. Current regulations are not enforcing and there is not much being done at the moment. Furthermore, public awareness on sustainable construction is relatively low to act as an encouraging factor. This is mainly due the concept being relatively new to the construction sector, which is a common barrier for most countries [16, 17]. Additionally, political situation due to the Cyprus problem has always had a negative influence on development and acted as a stalemating factor for keeping up with changes. However, at present time, there is a large scale construction activity going on in North Cyprus, both in terms of infrastructure and superstructure [18]. According to a director of a contracting firm (interview), construction technology used in North Cyprus is recently starting to renew itself. This was an unavoidable change in order to be able to respond to increased demand for property in the recent years. He added that, the industry and the country, as whole, have in some way been unfamiliar with technological changes and innovations, and most of the time it was implemented late. This is the case with sustainable construction. The industry has just started to move from conventional methods to certain modern methods but still, this is not adequate in terms of sustainability. The chance of introducing sustainability into the industry while the development is carrying on should not be missed. Though, there are certain barriers on the way to sustainable construction in North Cyprus.

Barriers to sustainable construction in North Cyprus mostly overlap with the problems of the sector itself. A senior politician highlighted that (interview) majority of the problems are the result of the development phase that the country is going through. This process is exposing the problems that persist within the regulations, economy, legislation and all of the sectors. Construction, as the most rapidly growing sector, is the most affected from these problems. The majority of these problems coupled with sustainability related matters create a bundle of barriers that are not impossible but challenging to overcome. Listed below are the barriers to sustainable construction in North Cyprus which were identified as a result of the interviews and the survey. Generally saying, all of the interviewees stated that the construction sector has to find permanent solutions for its own persisting problems before taking on a comprehensive transformation, like sustainability. Hence, proving that, these problems also act as barriers towards the achievement of sustainable construction as well as stalemating the efficient growth of the sector. Fig. 1, adapted from the "circle of blame" [11], summarises the current general picture of the sustainable construction in North Cyprus.

\subsection{Knowledge and Awareness}

The survey done in the form of questionnaire found 


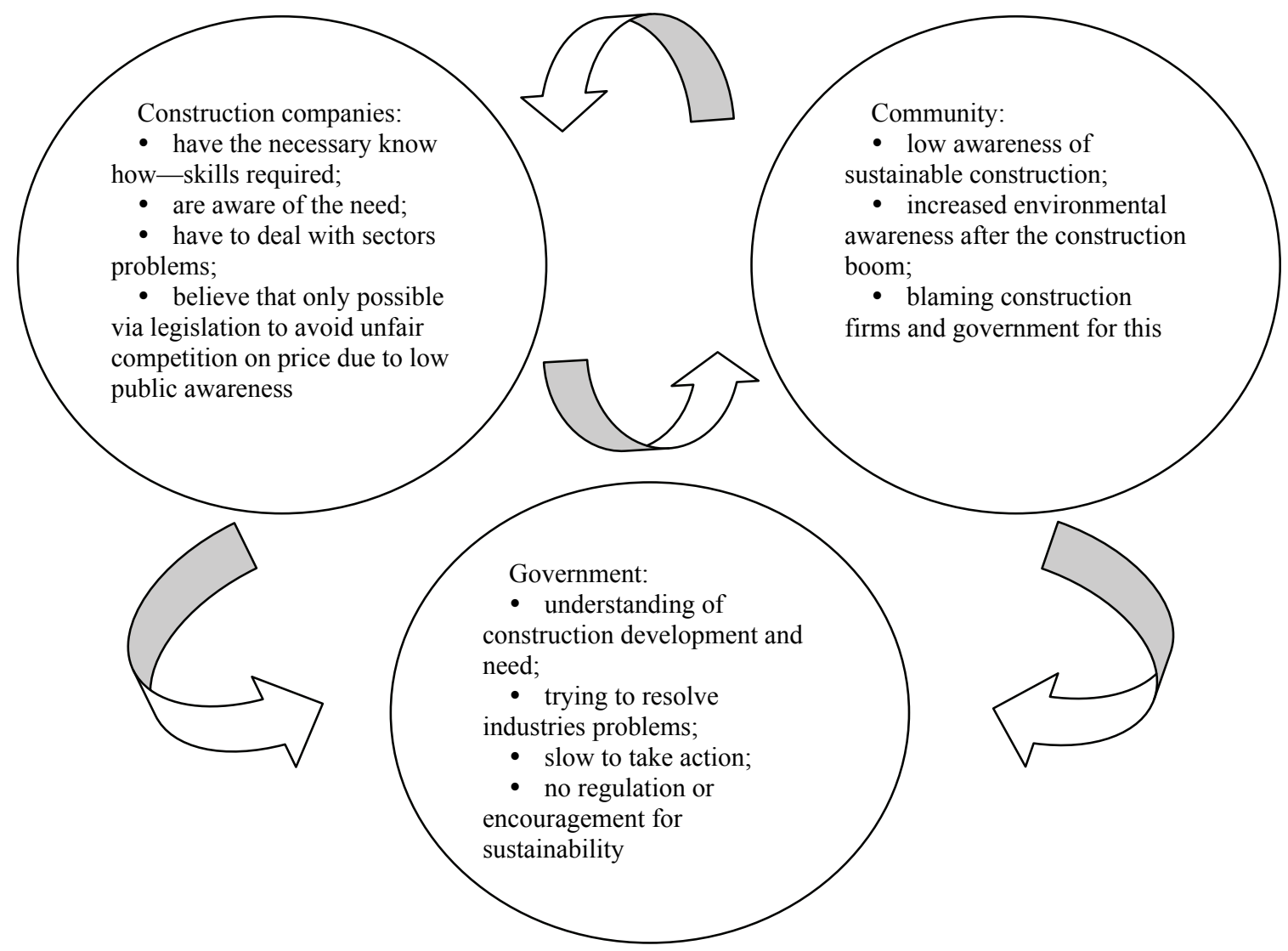

Fig. 1 Summary of the barriers and challenges for sustainable construction in North Cyprus.

out that $65 \%$ of the people are not familiar with the term "sustainable construction". Moreover, 35\% of the respondents (16 individuals) are familiar with the term, only two people could correctly explain what sustainable construction is. On the other hand, $75 \%$ of the people believe that the construction activities are adversely affecting the environment and nearly all stated that environmental objectives should be in priority, economic objectives ranked as the last. Additionally, majority of the interviewees stated that of the government, non-governmental organizations, construction sector and the community all have a role to play in order to achieve the objectives of sustainable construction.

As the results of the survey revealed, there is a partial lack of knowledge on the sustainability issue within the community. Yet, there is a considerable concern on the environmental issues, which is only one aspect of sustainable development, others being economic and social issues. Here, it is appropriate to say that there is a misunderstanding of the concept as well as lack of knowledge within the community.

Sustainability in the construction sector can only be achieved through participation between the community, government and the sector. Commitment by the citizens is only possible by spreading the necessary knowledge across by the use of informative campaigns. According to the developers interviewed, buyers at the marketplace looking to buy houses mostly prefer the least cost options. More expensive ones might have been built up to a higher standard and offer energy saving options such as insulated walls and double glazing, but in most cases this is not considered. Hence, this creates an unfair competition between the firms. They concluded that knowledge and awareness play a vital role in this kind of decision making, and it is the most important factor affecting the consumption patterns of people. This reveals 
another problem. Today, economic objectives mostly remain prior objective for the construction companies in North Cyprus due to increased competitiveness in the market. Sustainable construction practices increase the initial cost but pay back over the long run in terms of energy savings and low maintenance costs [19]. Buildings built to these standards will be on the market for a higher price. Interviewed developers mostly believe that, with the current consumption patterns, more expensive buildings shelter the risk of not being preferred by many. This is one of the main reasons which make actual implementation of sustainability into practice challenging, as for the companies, economic objectives are in most cases in priority and they can only be efficient in terms of business if they can market their products.

\subsection{Research and Development}

North Cyprus has always been an importer of the new technologies and innovations. The construction sector shares this feature as well, together with the others. There is not any research institutions present. Research and development is not possible due to the lack of necessary know how and above all-finance. Hence, the industry lacks the chance of developing any technologies that would serve the issue of sustainability. Apart from the lack of research institutions, there is not a proper co-ordination between the universities and the construction sector. As said by a contract manager (interview), establishment of such a link prevents the sector from being aware of the latest studies carried out about sustainability and being aware of the recent applications. So, the lack of research and development combined with the lack of co-ordination between the industry and the universities, constitute a barrier towards sustainable construction.

\subsection{Development Plans}

One of the main barriers for achieving sustainability in the construction sector is the lack of a general and comprehensive physical development plan. The developers interviewed argued that there is always an uncertainty about the development plans due to the fact that every appointed official makes changes, creating rise and falls on the land values and hence affecting the investment climate. On the contrary, one of the main components of achieving sustainability in construction sector is through the efficient land use. Development plans aim to put in order economic and social objectives of a country for a long period, taking into account the environmental issues. The crucial mistake done by the planners is that, they were only after physical appearance. Adverse economic effects or benefits, if there is any, are not taken into consideration. By doing this, future generations will be left with such a development that require regeneration within a short time. Economic, social and environmental burden of this will be heavy. So, the main issue is the lack of a long term master plan prepared with economic mentality. Traditionally, the only consideration was the physical appearance, which does not necessarily provide environmental protection. Regulations regarding height and area are rather prohibitive than being regulator. Despite being the capital city, four storeys is the limit in majority of Nicosia and also in other big cities as well. Even though the regulations were prepared with conservation seeking mentality, which believed that high rise structures spoil the appearance, it has nothing to do with conservation. On the contrary, high rise buildings that use less land can both provide more space for social use and prevent urban sprawl. Planned growth that will be enabled by a comprehensive development plan is extremely important as North Cyprus is a small country and hence easy to spoil in a short time, creating environmental degradation due to improper and unplanned use of the land. Tourism is one of the leading sectors in North Cyprus and makes a significant contribution to the national income. Therefore, unplanned, rapid growth can only add value in the short term but easily spoil the 
environment and physical structure and hence affect the tourism sector in the long term. This will in turn have adverse economic effects over time. Consequently, the lack of a comprehensive development plan as a significant problem of the industry constitutes another barrier to sustainable construction in North Cyprus.

\subsection{Lack of Necessary Legislations}

A contractor (interview) stated that in this present situation, sustainability cannot be avoided in our lives. It is not only essential in construction sector, but also in all other sectors as well. It is also inevitable because of the increasing population and scarce non-renewable resources. Furthermore, sustainability has also become a key in conflict solving. In almost all disputes, sustained solutions are sought after. This is because, the main objective is to handover to the future generations economically efficient and environmentally responsible sectors that will maximize the benefits for the society. He also added that, sustainability and sustainable construction have in the past decade gained significant importance in western countries. This is mainly due to environmental issues in addition to concerns about energy. Once they recognized the importance of these issues, governments aimed to put it into practice through the use of certain sanctions and policies. For example, when the energy crisis occurred in 1974 and the price of petrol was raised substantially, UK government at that time encouraged people to insulate their homes and brought the necessary legislations into life that would make insulation compulsory for the newly built. However, this is not obligatory in North Cyprus even though a huge amount of energy is spent for cooling in summers using HVAC (high voltage alternating current) air conditioning systems. The building codes do not make insulation obligatory and the external walls can be built in any way. In the past, prices of energy and water were below global standards and hence were lavishly spent. Now that the prices have begun to reach their real prices. Both the community and the construction firms will search for energy saving applications. Therefore, lack of comprehensive regulations promoting and encouraging sustainable construction mainly by the government are significant barriers, too.

\subsection{Problems of the Construction Sector}

Construction sector in North Cyprus is currently facing several problems. These problems, which are considered as factors that prevent the efficient growth of the sector, at the same time, slow down or even prevent the necessary changes to achieve sustainability. These problems included Bureaucratic structure of North Cyprus and lack of finance and financial instruments. As the implementation of the sustainability concept into the industry requires additional investment in machinery and equipment, and training of the employees is required. Other barriers included lack of adequate inspection on the construction sector and lack of the presence of an insurance system, which makes the contractor responsible for the job undertaken, in addition to the decrease in the number of qualified labour coming to work in North Cyprus, hence affecting the quality of the work.

North Cyprus is currently facing the problems associated with growth and development. Construction sector has been the fastest growing sector. Environmentalists and certain segments of the community were disturbed by the situation, stating the environment was being deteriorated. This view has quickly spread across by the media and hence created an unnecessary empathy towards the sector because the buildings are constructed on the lands that development plan allows. The result was the creation of two poles. On one hand, it is the environmentalist segment, opposing and protesting the current development trend. On the other hand, there is the opposing segment, who believes that for further economic development, investments are necessary. 
The positive outcome of this was the significant increase in the environmental awareness. The environment surely needs to be protected and that is what sustainable construction aims to, but, on the other hand, development is inevitable. In such a small island with limited resources, there remain a little number of sectors that can grow to a substantial size. These can be tourism, education and service sectors. In order to do so, development and construction is essential and land has to be used. Even though the government had attempts to resolve this problem by the use of temporary mandates on land use. Permanent, long term solution is crucial for efficient growth of the economy which would also aid sustainable development and construction.

\section{Conclusions}

The construction industry is one of the main contributor to national economies especially in a developing country such as North Cyprus. There is stringent need for construction in North Cyprus to advance the sustainability agenda. However, North Cyprus is facing numerous challenges in implementing sustainable construction policy. It is evident that current regulations are not enforcing and there is not much being articulated and implemented to advance sustainable construction. Besides, the fact that public awareness on sustainable construction is relatively low to act as an encouraging catalyst for change also influences the advancing. This is mainly due the concept being relatively new to the construction sector, which is a common barrier for most countries. Additionally, the political situation has always had a negative influence on development and acted as a stalemating factor for keeping up with changes. However, at present time, there is a large scale construction activity going on in North Cyprus, both in terms of infrastructure and superstructure, due to the increasing demand for property and the expanding tourism industry. To advance the sustainability agenda in the country, the construction industry must embrace technological developments and innovations. The chance of introducing sustainability into the industry while the development is carrying on should not be missed. Though, there are certain barriers on the way to sustainable construction in North Cyprus.

\section{References}

[1] Edwards, B., and Hyett, P. 2001. Rough Guide to Sustainability. London: RIBA (Royal Institute of British Architects) Companies Ltd.

[2] Common, M. 1995. Sustainability and Policy: Limits to Economics. Hong Kong: Cambridge University Press.

[3] CIOB (Chartered Institute of Building). 2004. Sustainability and Construction. Ascot: CIOB.

[4] Offori, G. 2007. "Construction in Developing Countries." Construction Management and Economics 25: 1-6.

[5] Kibert, J. C., and Wilson, A. 1999. Reshaping the Built Environment: Ecology, Ethics and Economics. Washington, D.C.: Island Press.

[6] Makenya, A. R. 1999. "Designing for Sustainable Buildings in Developing Countries: Problems and Priorities." In Durability of Building Materials and Components, edited by Lacasse, M. A., and Vanier, D. J. Ottawa: Institute for Research in Construction.

[7] Mukellef, G., and Oguz, O. 2007. Report on Construction Sector in Turkish Republic of Northern Cyprus. Nicosia: TRNC (Turkish Republic of Northern Cyprus) Prime Ministry.

[8] Manoliadis, O., Tsolas, I., and Nakou, A. 2006. "Sustainable Construction and Drivers of Change in Greece: A Delphi Study." Construction Management and Economics 24: 113-20.

[9] Brundtland, G. 1987. Our Common Future. Report of the World Commission on Environment and Developmen.

[10] Dresner, S. 2002. The Principles of Sustainability. London: Earthscan Publications.

[11] Myers, D. 2004. Construction Economics: A New Approach. London: E. \& F.N. Spon Ltd.

[12] Myers, D. 2005. "A Review of Construction Companies' Attitudes to Sustainability." Construction Management and Economics 23: 781-5.

[13] Prasad, D., and Hall, M. 2004. "Construction Challenge: Sustainability in Developing Countries." In RICS (Royal Institution of Chartered Surveyors) Leading Edge Series. London: RICS.

[14] Rodwin, L. 1987. Shelter, Settlement and Development. Nairobi: United Nations Centre for Human Settlements (Habitat).

[15] Yitmen, I. 2005. "Globalization and Competitive 
500 Perception and Challenges for Sustainable Construction in Developing Countries: North Cyprus Case

Strategies for Sustainable Construction in a Developing Country: North Cyprus Construction Industry." Presented at 10th International Conference on Durability of Building Materials and Components, Lyon, France.

[16] Plessis, D. C. 2007. "A Strategic Framework for Sustainable Construction in Developing Countries." Construction Management and Economics 25: 67-76.

[17] Eden, E. S. 1994. "Using Sustainable Development: The Business Case." Global Environmental Change 4 (2):
160-7.

[18] Yorucu, V. and Keles, R. 2007. "The Construction Boom and Environmental Protection in Northern Cyprus as a Consequence of the Annan Plan." Construction Management and Economics 25: 77-86.

[19] Kats, H. G. 2003. "Green Building Costs and Financial Benefits." Massachusetts Technology Collaborative. Accessed February 24, 2016. http://community-wealth.org/content/green-building-costs -and-financial-benefits. 